\title{
QuAlity Assurance Policies and Indicators FOR LONG-TERM CARE IN THE EUROPEAN UNION
}

\author{
ROBERTO DANDI
}

ENEPRI POLICY BRIEF No. 11

February 2012
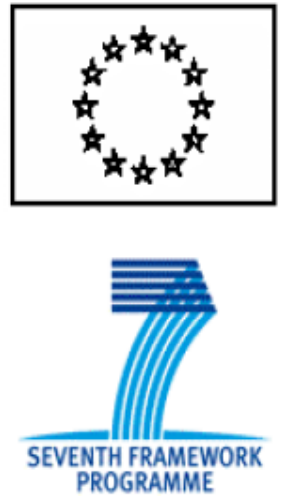

PROGRAMME
ENEPRI Policy Briefs extract the policy implications of research carried out by member institutes of the European Network of Economic Policy Research Institutes. Initiated by CEPS in 1999, ENEPRI conducts research on welfare and employment issues with the aim of diffusing research, coordinating research plans and increasing the awareness of the European dimension in national problems (see www.enepri.org). The research presented in this Policy Brief was conducted under the ANCIEN project (Assessing Needs of Care in European Nations), which focuses on the future of longterm care for the elderly in Europe. Funding for the project is received from the European Commission under the $7^{\text {th }}$ Framework Programme (FP7 Health-2007-3.2.2, Grant no. 223483). See the back page for more information "About ANCIEN". The views expressed are attributable only to the author in a personal capacity and not to any institution with which he is associated.

Available for free downloading from the CEPS website (www.ceps.eu) and ANCIEN website (http://www.ancien-longtermcare.eu/)

(C) Copyright 2012 Roberto Dandi 


\title{
QuAlity Assurance Policies AND Indicators FOR LONG-TERM CARE IN THE EUROPEAN UNION ROBERTO DANDI ${ }^{*}$
}

\author{
ENEPRI POLICY BRIEF NO. 11/FEBRUARY 2012
}

\begin{abstract}
Summary
This Policy Brief summarises findings from Work Package (WP) 5 of the ANCIEN project and its three objectives: first, collecting comprehensive information on national quality assurance policies and indicators in LTC systems in 15 EU member states; second, using the collected data to derive a typology of national systems on quality in LTC; and third, producing recommendations at all levels (European, national and local) to improve quality of LTC in Europe. The study has identified four clusters of countries based on the respective quality assurance policies and indicators. Comparing these results with the clusters identified in WP1, gaps between national policies for LTC and quality assurance policies have been identified. Also, some quality issues have been identified and analysed across Europe: professional integration, the quality of informal care, the transparency of quality assessment results, quality monitoring and professional education. This paper provides policy recommendations on these issues.
\end{abstract}

\section{Introduction}

The provision of high quality, long-term care (LTC) is an important policy goal. Yet considering the multidimensionality of the concept of quality, the vulnerability of many LTC recipients, the inevitable scarcity of resources and the importance of informal care, it is difficult to ensure high quality LTC. In this Policy Brief we report on quality assurance policies and indicators for LTC in the following EU countries: Austria, Estonia, Finland, France, Germany, Hungary, Italy, Latvia, Poland, Slovakia, Slovenia, Spain, Sweden, the Netherlands and the UK.

Data were collected in two ways: first, we developed a survey on quality assurance policies and indicators, and submitted it to all the partners involved in WP5 of the ANCIEN project; in a second step, survey data were analysed by LUISS to cluster countries according to their similarity in quality assurance policies. Also, we collected quality indicators used at the national level in each country and categorised them according to different criteria.

This Policy Brief is structured as follows: we first discuss the main findings of the analyses of survey data; then we derive the main implications for national and EU-level policies and interventions.

\section{Context for quality assurance policies}

According to the World Health Organization (2002), the goal of LTC is "to ensure that an individual who is not fully capable of long-term self-care can maintain the best possible quality of life, with the greatest possible degree of independence, autonomy, participation, personal fulfilment and human dignity”.

Unlike acute care, LTC does not eliminate diseases but aims at alleviating suffering, reducing discomfort, improving the limitations caused by disease and disability, and maintaining the best possible levels of physical and mental functioning.

These aims encompass a broad mix of services, such as personal care, health care and life management (e.g. shopping, medication management and transportation). They also span a wide range of resources,

\footnotetext{
* Roberto Dandi is a researcher of healthcare management at LUISS Business School, a Division of LUISS Guido Carli University in Rome.
} 
such as assistive devices (e.g. canes and walkers), more advanced technologies (e.g. emergency alert systems and computerised medication reminders) and home modifications (e.g. ramps and hand rails). As for the settings, LTC may be either institutional or home-based, and formal or informal.

Again unlike the acute sector, many LTC professionals are not specialised and are relatively unskilled. The sector is labour-intensive. Most LTC activities are performed by paraprofessionals with a variety of skills (home assistants, housekeepers, nurse assistants, activities staff or informal caregivers). Skilled workers (nurses, physicians, etc.) are involved to a lesser degree than in acute care. Medical devices are also significantly less complex and costly than those used for acute care. Many of the core LTC activities concern help with basic functioning or improving patient autonomy in performing basic or instrumental activities of daily living.

Any approach to assessing the quality of LTC needs to recognise all these differences from acute care, and the following in particular (IOM, 2000):

- $\quad$ Long-term care is both a health and a social issue. For the health service components of longterm care, judgments about the quality of care may emphasise the medical and technical aspects of care. For other facets of long-term care, judgments about the quality of care reflect the opinions and satisfaction of consumers.

- The potential and actual role of consumers is an essential element in long-term care. Thus the desired health outcomes depend on the patient's perspective and activation.

- $\quad$ For nursing homes and residential care settings, including assisted living, the physical environment of the facility can contribute to the physical safety and functional mobility of residents and, more broadly, to their quality of life.

- The very essence of LTC, more specifically the persistent nature of the disabilities and of the chronic conditions, has an impact on i) the development of interpersonal relationships among providers, families and patients; ii) the physical adaptation of the home or the infrastructure of facilities to accommodate or attend patients on a longstanding basis; and iii) the greater need for coordination among different types of carers.

In WP5 of the ANCIEN project, we took into account all these variables in understanding diverse national approaches to promoting the quality of LTC. A caveat is that having a sound quality assurance policy does not automatically guarantee that a country will have high quality LTC. We defined quality as a multidimensional concept encompassing the effectiveness of care, patient safety, responsiveness (or patient-centeredness) and the coordination of providers. The first three dimensions have been identified by the OECD (Arah et al., 2006) as the main issues of any approach to quality in health care. We included coordination as a fourth dimension because we believe that quality in LTC, given the complexity of LTC, must also include the coordination of different providers. Continuity of care (across social care and health care, as well as across levels of care) is a key issue in ensuring the quality of LTC.

As may be expected, there is a wide variety of policy measures across European countries (and within countries in some cases). Comparing quality assurance policies among EU member states is difficult for several reasons (European Commission, 2008):

- $\quad$ Member states use a variety of definitions of LTC that do not always concur.

- $\quad$ There are different levels of organisation and varying divisions of responsibility between the public sector, the private sector and the family.

- $\quad$ There are assorted interventions to address the elderly and their families that may be related to LTC systems: prevention measures, active ageing, autonomy promotion and empowerment, social assistance, family support, etc.

An analysis of the context for quality assurance policies is therefore key to understanding them across countries. The context was analysed in WP1 of the ANCIEN project (Kraus et al., 2010). WP1 identified four clusters of countries according to the form of LTC used and financing systems (Table 1), and four clusters according to the organisation of LTC and public spending on it (Table 2). 
Table 1. Country clusters based on LTC use and financing

\begin{tabular}{ll}
\hline Cluster & LTC use and financing \\
\hline $\begin{array}{l}\text { Cluster 1: Belgium, Czech } \\
\text { Republic, Germany, Slovakia }\end{array}$ & $\begin{array}{l}\text { Oriented towards informal care, a low level of private financing (low } \\
\text { spending, low private funding, high IC use, high IC support, modest } \\
\text { cash benefits) }\end{array}$ \\
$\begin{array}{l}\text { Cluster 2: Denmark, the } \\
\text { Netherlands, Sweden }\end{array}$ & $\begin{array}{l}\text { Generous, accessible and formalised (high level of spending, low } \\
\text { private funding, low IC use, high IC support, modest cash benefits) }\end{array}$ \\
$\begin{array}{l}\text { Cluster 3: Austria, Finland, } \\
\text { France, Spain, the UK }\end{array}$ & $\begin{array}{l}\text { Oriented towards informal care, high level of private financing } \\
\text { (medium spending, high private funding, high IC use, high IC } \\
\text { support, high cash benefits) }\end{array}$ \\
Cluster 4: Hungary, Italy & $\begin{array}{l}\text { High private financing, informal care seems a necessity (low level of } \\
\text { spending, high private funding, high IC use, low IC support, medium } \\
\text { cash benefits) }\end{array}$ \\
\hline
\end{tabular}

Note: IC refers to informal care.

Source: Kraus et al. (2010).

Table 2. Country clusters based on LTC organisational depth and financial generosity

\begin{tabular}{ll}
\hline Cluster & $\begin{array}{l}\text { Organisational depth and financial } \\
\text { generosity }\end{array}$ \\
\hline $\begin{array}{l}\text { Cluster 1: Belgium, Denmark, France, Germany, the } \\
\text { Netherlands, Sweden (corresponds to WP1 cluster 2 based } \\
\text { on LTC use) }\end{array}$ & $\begin{array}{l}\text { Profound organisational depth, high level of } \\
\text { financial generosity }\end{array}$ \\
$\begin{array}{ll}\text { Cluster 2: Austria, Finland, Italy, Latvia, Slovenia, Spain, } \\
\text { UK (corresponds to WP1 cluster } 3 \text { based on LTC use) }\end{array}$ & $\begin{array}{l}\text { Medium organisational depth, medium } \\
\text { level financial generosity }\end{array}$ \\
$\begin{array}{l}\text { Cluster 3: Bulgaria, Estonia, Czech Republic, Slovakia } \\
\text { (corresponds partly to WP1 cluster } 1 \text { based on LTC use) }\end{array}$ & $\begin{array}{l}\text { Profound organisational depth, low level of } \\
\text { financial generosity }\end{array}$ \\
$\begin{array}{l}\text { Cluster 4: Hungary, Lithuania, Poland, Romania } \\
\text { (corresponds in part to WP1 cluster 4 based on LTC use) }\end{array}$ & $\begin{array}{l}\text { Shallow organisational depth, low level of } \\
\text { financial generosity }\end{array}$ \\
\hline
\end{tabular}

Source: Kraus et al. (2010).

In WP5, we also identified four clusters based on quality assurance policies across countries, as shown in Table 3.

Table 3. Country clusters based on LTC quality assurance policies and indicators

\begin{tabular}{ll}
\hline Cluster & Policies on quality and indicators \\
\hline $\begin{array}{l}\text { Cluster 1: Estonia, France, Germany, } \\
\text { Latvia, the Netherlands, Slovakia, UK }\end{array}$ & $\begin{array}{l}\text { Quality assurance policies for formal LTC (both residential } \\
\text { and at home), outcome-related policies and indicators, and } \\
\text { guidelines about the quality of LTC; Latvia actually belongs } \\
\text { to cluster 1 but has features of cluster } 2 \text { as well }\end{array}$ \\
$\begin{array}{ll}\text { Cluster 2: Austria, Finland, Hungary, } \\
\text { Spain, Sweden }\end{array}$ & $\begin{array}{l}\text { Quality assurance policies for formal LTC as in cluster 1, but } \\
\text { with a focus on monitoring the quality of processes and } \\
\text { inputs rather than of outcomes; there are some policies on the } \\
\text { quality of informal care }\end{array}$ \\
$\begin{array}{l}\text { Lack of quality assurance policies and indicators } \\
\text { Cluster 3: Poland, Slovenia }\end{array}$ & $\begin{array}{l}\text { Quality assurance policies for formal LTC and existing } \\
\text { guidelines on the quality of LTC; a lack of policies and } \\
\text { indicators on responsiveness to patient needs. }\end{array}$ \\
\hline
\end{tabular}

Source: Dandi et al. (2012). 
What is the relation between the type of LTC system, and quality assurance policies and indicators? The results are mixed.

Some of the countries in Table 1 that belong to WP1 cluster 1 (Germany, Slovakia and Estonia) and WP1 cluster 3 (France and UK) correspond in WP5 to cluster 1, which is characterised by quality assurance policies in formal care, with policies aimed at quality in outcomes and quality guidelines. These countries, in line with the description of WP1 clusters 1 and 3, are distinguished by the high use of and high level of support for informal care. In WP5, however, most of them do not feature a similar strategy concerning quality assurance policies and indicators for informal care. Apparently, there is a gap to be filled in these countries: since informal care is that important, a strategy on quality ought to be developed in this field.

The Netherlands, by contrast, is perfectly consistent with its strategy. In WP1 it belongs to cluster 2, which is composed of countries that are generous in public spending and invest a lot in formal LTC (both residential and home care). This is consistent with categorising the Netherlands in WP5 cluster 1, where the quality of formal care is a key factor.

As for their use of informal care, Austria, Spain and Finland (WP1 cluster 3) would also be expected to invest in the quality of informal care. This is somewhat the case, and hence they belong to WP5 cluster 2, which is mainly characterised by input-process indicators but also by quality assurance policies in informal care.

Based on our data, Poland and Slovenia focus on private spending and have not developed national policies or indicators on the quality of care. Likewise, Italy relies on private spending and informal care but has not developed policies on informal care.

Also, if we look at Table 3, we see that Germany, the Netherlands and France (WP1 cluster 1) all belong to WP5 cluster 1 (with outcome-based policies and indicators on the quality of formal care). This is consistent with their high levels of public spending and good organisational structure for the provision of LTC.

\section{Evidence and analysis}

By analysing 15 EU countries, we identified the main features of quality assurance policies outlined below.

Integration. LTC systems are so complex and involve so many stakeholders and decision-makers that no one is fully responsible for LTC. Furthermore, LTC is intrinsically a multidimensional activity that requires multiple competencies to carry it out effectively, the coordination of LTC providers is crucial to guaranteeing a high level of quality (MISSOC, 2009). Coordination is actually related to several key issues for quality in LTC:

1) timeliness, that is the degree to which patients are able to obtain care promptly. The coordination of care is critical for timeliness when a patient needs to go through different stages of care and across providers;

2) continuity, that is the extent to which the health care specified for users, over time, is coordinated across providers and institutions; and

3) integration between primary and secondary care, and between health care and social care. Without this, quality in coordination may be undermined.

In different countries there is a growing awareness that the quality of LTC is based on an effective integration of health and social services. On average (see WP1 data of the ANCIEN project in Kraus et al., 2010), there is a medium level of integration of the components of LTC. Yet there are fewer indicators for assessing the quality of coordination than for other dimensions (such as effectiveness and responsiveness). According to country reports, transitions from/to hospitals is an issue to be addressed. 
Consistency between LTC policies and LTC quality assurance policies. Consistency is a central issue in some countries because of the lack of integration of responsibilities. LTC policies and LTC quality assurance policies may be developed by different actors. Also, quality assurance policies may not reflect the actual use of LTC.

As discussed in the above section, countries with high scores in the use of formal care and high levels of public spending on LTC have consequently invested in quality assurance policies in formal care. Countries with high co-payments are less prepared for quality systems, and should invest more in quality assurance policies in home-based and informal care. The latter aspect may also be relevant for countries with high levels of public spending that are trying to increase the role of informal care.

Transparency. Today, in LTC the role of the user/patient is often very limited. Therefore, it is very important not only to take into account the patients' needs but also their expectations, including the desire for choice. To do so patients need to be informed about the quality of the providers. This can be done by improving transparency and making better information available to users (European Commission, 2008; MISSOC, 2009). Our results, however, reveal that most countries do not provide public data about the quality of care in LTC institutions (Table 4; see also Box 1).

Table 4. National visibility of providers' quality indicators (question 4)

\begin{tabular}{|c|c|c|c|c|c|c|c|c|c|c|c|c|c|c|c|}
\hline & \multicolumn{15}{|c|}{ Country } \\
\hline & 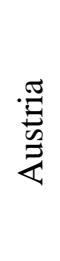 & 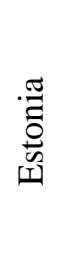 & 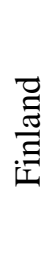 & 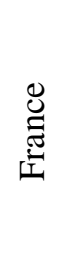 &  & $\begin{array}{l}\overrightarrow{\widetilde{d}} \\
\text { 品 } \\
\text { 至 }\end{array}$ & 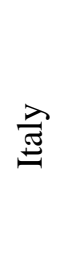 & 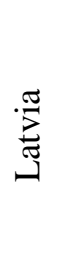 & $\begin{array}{l}\vec{T} \\
\text { ] } \\
\text { O } \\
0\end{array}$ & $\begin{array}{l}\frac{\pi}{\pi} \\
\frac{\pi}{0} \\
\frac{a}{\omega}\end{array}$ & 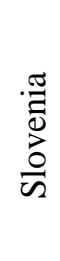 & $\begin{array}{l}\text { 䒕 } \\
\text { के }\end{array}$ & 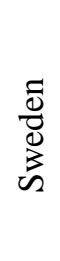 & 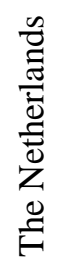 & 光 \\
\hline $\begin{array}{l}\text { National } \\
\text { visibility }\end{array}$ & $\mathbf{X}$ & $\mathbf{X}$ & $\mathbf{X}$ & $\mathbf{X}$ & $\mathbf{V}$ & $\mathbf{V}$ & $\mathbf{X}$ & $\mathbf{V}$ & $X$ & $\mathbf{X}$ & $\mathbf{X}$ & $\mathbf{X}$ & $\mathbf{V}$ & $\mathbf{V}$ & $\mathbf{V}$ \\
\hline
\end{tabular}

Source: Dandi et al. (2012).

\section{Box 1. Transparency in Germany}

The Long-term Care Development Act of 2008 stipulates that the results of quality inspections have to be published on the Internet and in other forms in a manner that is easily understandable and consumerfriendly. The Associations of the LTCI (Long-term Care Insurance) funds at the Länder level are responsible for publication. The criteria for publishing inspection results were agreed by the parties within the framework of long-term care provision. The agreement for publishing the results of the inspections of ambulatory home-care services (Care-Transparency Agreement - Ambulatory) came into force on 1 February 2009 and the agreement concerning institutional care on 1 January 2009. The transparency agreements encompass the kinds of quality criteria used for the public report (appendix 1 of the agreement), the appraisal system (appendix 2), the instruction manual (appendix 3) and the presentation of the results (appendix 4). The quality criteria used for the transparency report are a selection of the criteria assessed by the Medical Review Boards during their inspections. Besides the report on quality, the Medical Review Boards send the relevant dataset with the quality criteria for the transparency report to the Association of LTCI funds at the Länder level. The data is then used to write the transparency report. The care facilities receive the written report from the Associations of LTCI funds and have the possibility to include further information in order to clarify issues in dispute. Afterwards the transparency report is made publicly available on the Internet.

Source: Schulz (2012). 
Quality of informal care. In many countries, informal caregivers sacrifice part of their lives to take care of their elderly family members. A quality LTC system therefore should not only be based on the assessment of the patient's needs. As the bulk of LTC is provided by informal caregivers and is dependent upon their health and well-being, caregivers' needs must also be assessed and satisfied.

Our results show that most interventions entail financial support for buying devices, training/counselling of the informal caregivers, and assessing the health conditions and personal needs of patients (see Table 5).

Table 5. Policy options for supporting the quality of informal care

\begin{tabular}{|c|c|c|c|c|c|c|c|c|c|c|c|c|c|c|c|c|}
\hline Policy & \multicolumn{15}{|c|}{ Country } & \multirow[t]{2}{*}{ Total } \\
\hline &  & 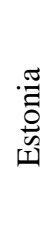 & 尔 & 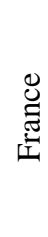 &  & 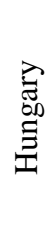 & $\vec{\Xi}$ & $\sum_{\pi}^{\frac{\pi}{S}}$ & 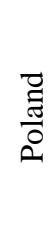 & $\frac{. \pi}{\frac{\pi}{\pi}}$ & $\frac{\pi}{\frac{\pi}{0}}$ & $\begin{array}{l}\text { : } \\
\text { की }\end{array}$ & 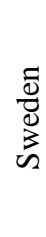 & 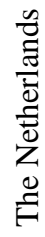 & 岁 & \\
\hline $\begin{array}{l}\text { Assessment of } \\
\text { LTC needs and } \\
\text { personalised } \\
\text { self-care plans }\end{array}$ & V & V & V & V & $\mathrm{X}$ & $\mathrm{X}$ & $\mathrm{X}$ & $\mathbf{X}$ & $\mathbf{X}$ & V & $\mathbf{X}$ & $\mathbf{X}$ & V & V & V & 8 \\
\hline $\begin{array}{l}\text { Courses for } \\
\text { informal } \\
\text { caregivers }\end{array}$ & $\mathbf{V}$ & $\mathbf{V}$ & $\mathbf{V}$ & $\mathbf{X}$ & $\mathbf{V}$ & $\mathbf{X}$ & $\mathbf{V}$ & $\mathbf{V}$ & $\mathbf{X}$ & V & $\mathbf{X}$ & $\mathbf{X}$ & $\mathbf{V}$ & $\mathbf{V}$ & V & 10 \\
\hline $\begin{array}{l}\text { Statutory visits } \\
\text { in the home } \\
\text { environment } \\
\text { by health and } \\
\text { social care } \\
\text { personnel }\end{array}$ & $\mathbf{V}$ & $\mathbf{X}$ & $\mathbf{V}$ & $\mathbf{X}$ & $\mathbf{V}$ & $\mathbf{X}$ & $\mathbf{X}$ & $\mathbf{X}$ & $\mathbf{X}$ & V & $\mathbf{X}$ & $\mathrm{X}$ & V & $\mathrm{X}$ & $\mathrm{X}$ & 5 \\
\hline $\begin{array}{l}\text { Awareness } \\
\text { raising } \\
\text { campaigns } \\
\text { about quality }\end{array}$ & $\mathbf{X}$ & $\mathbf{V}$ & $\mathbf{V}$ & $\mathbf{V}$ & $\mathbf{V}$ & $\mathbf{X}$ & $\mathbf{V}$ & $\mathbf{V}$ & $\mathbf{X}$ & $\mathbf{V}$ & $\mathbf{X}$ & $\mathbf{X}$ & $\mathbf{V}$ & $\mathbf{V}$ & $\mathbf{V}$ & 10 \\
\hline $\begin{array}{l}\text { Financial } \\
\text { support for } \\
\text { buying } \\
\text { technologies } \\
\text { for self-care } \\
\text { and home } \\
\text { devices }\end{array}$ & $\mathbf{V}$ & $\mathbf{V}$ & $\mathbf{V}$ & $\mathbf{V}$ & V & $\mathbf{X}$ & $\mathbf{V}$ & $\mathbf{V}$ & $\mathbf{X}$ & V & $\mathbf{X}$ & $\mathbf{X}$ & V & V & V & 11 \\
\hline Other & $\mathbf{X}$ & $\mathbf{X}$ & $\mathbf{X}$ & $\mathbf{X}$ & $\mathbf{X}$ & $\mathbf{X}$ & $\mathbf{X}$ & $\mathbf{V}$ & $\mathbf{X}$ & $\mathbf{V}$ & $\mathbf{X}$ & $\mathbf{X}$ & V & $\mathbf{V}$ & $\mathbf{X}$ & 4 \\
\hline
\end{tabular}

Source: Dandi et al. (2012).

Monitoring. Monitoring systems are needed to support the evaluation of quality, promote informed policies and provide feedback to the various actors in the field (European Commission, 2008). On average, monitoring for authorisation/accreditation occurs every three years (ranging from one to five years) (Table 6). 
Table 6. Monitoring frequency (in years) for authorisation/accreditation

\begin{tabular}{|c|c|c|c|c|c|c|c|c|c|c|c|c|c|c|c|}
\hline & \multicolumn{15}{|c|}{ Country } \\
\hline & $\frac{\sqrt[\pi]{G}}{\stackrel{\Xi}{5}}$ & 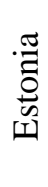 & $\underset{\text { 모 }}{\stackrel{\widetilde{J}}{\Xi}}$ & 总 & 㐫 & $\begin{array}{l}\text { 怘 } \\
\text { 品 } \\
\text { 至 }\end{array}$ & $\frac{\lambda}{ \pm}$ & $\sum_{\pi}^{\pi}$ & 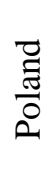 & $\begin{array}{l}\frac{\pi}{3} \\
\frac{\pi}{2} \\
\frac{0}{n} \\
\frac{0}{n}\end{array}$ & $\begin{array}{l}\cdot \frac{\pi}{3} \\
\frac{0}{0} \\
\frac{0}{\omega}\end{array}$ & $\begin{array}{l}\text {.ే } \\
\text { जी }\end{array}$ & 胥 & 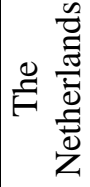 & 岇 \\
\hline $\begin{array}{l}\text { Monitoring } \\
\text { frequency } \\
\text { (years) }\end{array}$ & 5 & 1 & na & 7 & 3 & 2 & 5 & 5 & na & 1 & 3 & na & na & 1 & 5 \\
\hline
\end{tabular}

Source: Dandi et al. (2012).

Education. Competent staff is a key factor for the quality of LTC providers. Yet LTC needs staff who are specialised in the care of the elderly. Among the many professional roles that are involved in LTC, the most highly qualified staff seem to be GPs. Ten countries report that GPs are provided specific education for LTC (Box 2). Fewer countries report the same for other roles. Nurses also play a pivotal role in LTC facilities and home nursing care. The shortage of nurses is a threat to the quality of LTC (Box 3).

\section{Box 2. Specific education for LTC staff in the Netherlands}

To improve the level of medical care in nursing homes, the Ministry of Health, Welfare and Sports decided to acknowledge nursing home medicine as a new specialist field of medicine in 1990. The Netherlands became the first country in the world where nursing homes started to employ specially trained physicians on a permanent basis (1 full-time physician for every 100 patients). The number of trainees who started the mandatory training course has increased annually. It rose from 15 to 100 between 1989 and 2009. In 2007 the Minister of Health, Welfare and Sports decided to extend the duration of the training course from two years to three.

Source: Mot (2012).

\section{Box 3. Quality of personnel: Debate on the shortage of nurses in Germany}

In view of demographic developments a significant shortage of nurses is expected in the future in Germany. Caregiving is a hard job and the prestige and wages of nurses are relatively low. Thus measures are necessary to increase the prestige of this type of employment, to increase the wages and to stimulate enthusiasm among potential employees for this kind of work. The Federal Ministry of Health plans a bundle of initiatives to meet the challenges. The Ministry has prolonged financial support for individuals who join the vocational retraining programme and discussed a reorganisation of the guidelines for the vocational training of geriatric nurses and state approved nurses. It has also looked at how to integrate migrants into the field of caring, how to increase the wages (the implementation of minimum wages) and how to improve the working conditions. These initiatives may be one aspect of new reforms to the longterm care system.

Source: Schulz (2012). 


\section{Policy options to improve the quality of LTC}

There may be many ways to tackle a certain problem concerning quality and this research may not be specific enough to pinpoint the best. Nevertheless, below we identify some policy recommendations to address specific quality issues in LTC.

\section{Integration}

- $\quad$ Policy-makers should stimulate the development of methods to measure the integration of LTC responsibilities and the collection of more precise data on integration.

- $\quad$ National policy-makers should promote the integration of the currently scattered responsibilities at all levels. LTC should be addressed as a national priority. An integrated strategic plan on LTC (including strategies on quality) should be developed at the national level and implemented by local authorities.

- $\quad$ The European Commission and the national authorities should promote the diffusion of best practices. Examples in this regard are the project "Medtogether" in Austria and Law §92b SCBXI on Integrated Care in Germany.

- $\quad$ National policy-makers should support the use of information and communication technology (ICT) for the integration of all the actors involved in LTC, including patients. The use of ICT has the potential to reduce risks and increase quality by standardising care processes, enabling the remote monitoring of patients and empowering the patient in self-treatment (WP4 deliverables).

- Local health and social authorities could organise the provision of services around the patient by identifying a case manager. In some countries this may be the GP, while in others, such as Estonia, it may be a specialist (gerontologist).

\section{Consistency between LTC policies and those on the quality of LTC}

- $\quad$ Countries with a large diffusion of informal LTC should address the issue by having a quality assurance policy for informal care (to protect caregivers and care recipients) and for supporting informal caregivers through services (e.g. respite care). (See the discussion above on the quality of informal care.)

\section{Transparency}

- The European Commission and the national authorities should promote/recommend transparency on information about the results of quality assessments. A national commission for the selection of shared criteria for the quality assessment would be needed, to avoid criticism about methodology.

- $\quad$ The European Commission and the national authorities should promote the diffusion of best practices on transparency. In Germany, the quality assessment results of LTC providers have been published online since 2008 (see Box 1). In the Netherlands, data about the quality assessment results of LTC organisations are publicly available on a voluntary basis. In 2008, $49 \%$ of health care providers were already publishing their data. The long-term target is to reach $100 \%$. In Slovakia, data about the quality assessment results of LTC organisations will become publicly available as the new legislation becomes effective from 2013. In the UK, a system providing quality ratings for providers began operating in 2003 for formal institutional care and 2005 for formal domiciliary care. Since June 2010, however, it has no longer been in operation and there is no news about a replacement programme (Dandi et al., 2012). 


\section{Quality of informal care}

- National and local authorities could promote networking among local authorities, volunteer organisations and families.

- The European Commission and the national authorities could promote the diffusion of best practices in this regard. Examples include the experience of the municipalities in Sweden, the Mezzo association for informal caregivers in the Netherlands and national training programmes, such as "Caring with Confidence" in the UK (even if it has been discontinued).

- Local authorities should assess the needs of informal caregivers to ensure personalised support is provided in terms of caregiver training, statutory visits and prevention campaigns. For instance, in the UK the NHS (National Health Service) website provides informal caregivers lengthy information on medical devices and assisting technologies, on how to move and handle the patients. ${ }^{1}$

- $\quad$ National authorities could promote the diffusion of standard information and communication technologies for remote monitoring, thus alleviating the burdens of informal caregivers.

\section{Monitoring}

- $\quad$ The European Commission should recommend that member states monitor providers according to the different dimensions of quality: the effectiveness of care, safety and responsiveness to patient's needs.

- Monitoring frequency should be standardised across countries to enable comparisons of the impact of quality assurance policies at the national level on the specific dimensions of quality of care.

\section{Education}

- National authorities should promote the development of a standard curriculum for each LTC role.

- $\quad$ The European Commission should promote research studies on best practices for the training, hiring and retention of geriatric nurses as well as for other LTC roles in LTC systems and providers.

\footnotetext{
${ }^{1}$ See the NHS website (http://www.nhs.uk/carersdirect/guide/practicalsupport/pages/othersupport.aspx).
} 


\section{References}

Arah, O.A., G.P. Westert, J. Hurst and N.S. Klazinga (2006), “A conceptual framework for the OECD Health Care Quality Indicators project”, International Journal for Quality in Health Care, Vol. 18, Supplement 1, pp. 5-13.

Dandi, R., E. Mot and P. Willemé (eds) (2012), Long-Term Care Quality Policies in the European Union, ENEPRI Research Report, CEPS, forthcoming.

European Commission (2008), Long Term Care in the European Union, DG for Employment, Social Affairs and Equal Opportunities, Brussels (http://ec.europa.eu/social/BlobServlet? docId=768\&langId=en).

Institute of Medicine (IOM) (2000), Improving the Quality of Long-Term Care, IOM Report, IOM, Washington, D.C. (http://www.iom.edu/Reports/2000/Improving-the-Quality-of-Long-TermCare.aspx).

Kraus, M., M. Riedl, E. Mot, P. Willemé, G. Röhrling and T. Czypionka (2010), A Typology of LongTerm Care Systems in Europe, ENEPRI Research Report No. 91, CEPS, Brussels (http://www.ancien-longtermcare.eu/).

Mot, E. (2012), “The Netherlands”, in R. Dandi, E. Mot and P. Willemé (eds), Long-Term Care Quality Policies in European Countries, ENEPRI Report (forthcoming).

Mutual Information System on Social Protection in the EU Member States (MISSOC) (2009), MISSOC analysis (2009): Long Term Care, MISSOC, Brussels, August (http://ec.europa.eu/social/BlobServlet?docId=4320\&langId=en).

Schulz, E. (2012), Quality assurance in long-term care in Germany, ENEPRI report (forthcoming).

World Health Organization (WHO) (2002), Lessons for long term care policies, WHO, Geneva (http://whqlibdoc.who.int/hq/2002/WHO_NMH7CCL_02.1.pdf). 


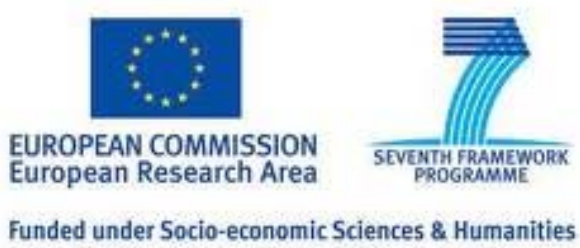

Funded under Socio-economic Sciences \& Humanities

\section{ANCIEN}

Assessing Needs of Care in European Nations

FP7 HEALTH-2007-3.2-2

L aunched in January 2009, ANCIEN is a research project financed under the 7th EU Research Framework Programme. It runs for a 44-month period and involves 20 partners from EU member states. The project principally concerns the future of long-term care (LTC) for the elderly in Europe and addresses two questions in particular:

1) How will need, demand, supply and use of LTC develop?

2) How do different systems of LTC perform?

The project proceeds in consecutive steps of collecting and analysing information and projecting future scenarios on long-term care needs, use, quality assurance and system performance. State-of-the-art demographic, epidemiological and econometric modelling is used to interpret and project needs, supply and use of long-term care over future time periods for different LTC systems.

Work Packages. The project started with collecting information and data to portray long-term care in Europe (WP 1). After establishing a framework for individual country reports, including data templates, information was collected and typologies of LTC systems were created. The collected data will form the basis of estimates of actual and future long term care needs in selected countries (WP 2). WP 3 builds on the estimates of needs to characterise the response: the provision and determinants of formal and informal care across European long-term care systems. Special emphasis is put on identifying the impact of regulation on the choice of care and the supply of caregivers. WP 6 integrates the results of WPs 1, 2 and 3 using econometric micro and macro-modelling, translating the projected needs derived from WP2 into projected use by using the behavioral models developed in WP3, taking into account the availability and regulation of formal and informal care and the potential use of technological developments.

On the back of projected needs, provisions and use in European LTC systems, WP 4 addresses developing technology as a factor in the process of change occurring in long-term care. This project will work out general principles for coping with the role of evolving technology, considering the cultural, economic, regulatory and organisational conditions. WP 5 addresses quality assurance. Together with WP 1, WP 5 reviews the policies on LTC quality assurance and the quality indicators in the EU member states, and assesses strengths, weaknesses, opportunities and threats of the various quality assurance policies. Finally WP 7 analyses systems performance, identifying best practices and studying trade-offs between quality, accessibility and affordability.

The final result of all work packages is a comprehensive overview of the long term care systems of EU nations, a description and projection of needs, provision and use for selected countries combined with a description of systems, and of quality assurance and an analysis of systems performance.

\section{Principal and Partner Institutes}

CEPS is responsible for administrative coordination and dissemination of the general results (WP 8 and 9). The Belgian Federal Planning Bureau (FPB) and the Netherlands Bureau for Economic Policy Analysis (CPB) are responsible for scientific coordination. Other partners include: German Institute for Economic Research (DIW); Netherlands Interdisciplinary Demographic Institute (NIDI); Fundación de Estudios de Economía Aplicada (FEDEA); Consiglio Nazionale delle Ricerche (CNR); Universitá Luiss Guido CarliLuiss Business School (LUISS-LBS); Institute for Advanced Studies (IHS); London School of Economics and Political Science- Personal Social Services Research Unit (PSSRU); Istituto di Studi e Analisi Economica (ISAE); Center for Social and Economic Research (CASE); Institute for Economic Research (IER); Social Research Institute (TARKI); The Research Institute of the Finnish Economy (ETLA); Université de Paris-Dauphine-Laboratoire d’Economie et de Gestion des organisations de Santé (DAUPHINE- LEGOS); University of Stockholm, Department of Economics; Karolinska InstituteDepartment of Medecine, Clinical Epidemiology Unit ; Institute of Economic Research, Slovak Academy of Sciences (SAS-BIER); Center for Policy studies (PRAXIS). Most of the ANCIEN partners are members of the European Network of Economic Policy Research Institutes (ENEPRI). 